\title{
Simultaneous Energy Savings and IEQ Improvements in Relocatable Classrooms
}

MG Apte ${ }^{1 *}$, D Dibartolomeo ${ }^{1}$, T Hotchi $^{1}$, AT Hodgson ${ }^{1}$, SM Lee ${ }^{1}$, SM Liff ${ }^{2}$, LI Rainer $^{3}$, DG Shendell ${ }^{1}$, DP Sullivan ${ }^{1}$, and WJ Fisk ${ }^{1}$

${ }^{1}$ Indoor Environment Dept., Lawrence Berkeley National Laboratory, Berkeley, CA, USA

${ }^{2}$ Massachusetts Institute of Technology, Boston, MA

${ }^{3}$ Davis Energy Group, Davis, CA

June 4, 2003

*Contact: MGApte@lbl.gov, 510-486-4669 (office), 510-486-6658 (FAX) 


\begin{abstract}
Relocatable classrooms (RCs) are commonly used by school districts with changing demographics and enrollment sizes. We designed and constructed four energy-efficient RCs for this study to demonstrate technologies with the potential to simultaneously improve energy efficiency and indoor environmental quality (IEQ). Two were installed at each of two school districts, and energy use and IEQ parameters were monitored during occupancy. Two RCs (one per school) were finished with materials selected for reduced emissions of toxic and odorous volatile organic compounds (VOCs). Each had two HVAC systems, operated on alternate weeks, consisting of a standard heat-pump system and an indirect-direct evaporative cooling (IDEC) system with gas-fired hydronic heating. The IDEC system provides continuous outside air ventilation at $\geq 15 \mathrm{CFM}\left(7.5 \mathrm{~L} \mathrm{~s}^{-1}\right)$ person $^{-1}$, efficient particle filtration while using significantly less energy for cooling. School year long measurements included: carbon dioxide $\left(\mathrm{CO}_{2}\right)$, particles, VOCs, temperature, humidity, thermal comfort, noise, meteorology, and energy use. IEQ monitoring results indicate that important ventilation-relevant indoor $\mathrm{CO}_{2}$ and health-relevant VOC concentration reductions were achieved while average cooling and heating energy costs were simultaneously reduced by $50 \%$ and $30 \%$, respectively.
\end{abstract}




\section{INTRODUCTION}

LBNL-52690

Energy efficiency in buildings is a key design consideration regulated by governmental agencies. Buildings also can be designed to explicitly improve indoor environmental quality (IEQ). Designs achieving good IEQ can be expected to have beneficial effects with respect to occupant health, work performance and absenteeism (Fisk, 2000). This study was conducted with the goal of quantifying and demonstrating technologies with the potential to simultaneously improve energy efficiency and IEQ using new relocatable (modular or portable) classrooms as the exemplary buildings. Relocatable classrooms (RCs) are particularly well suited for this demonstration because they are self-contained structures with dedicated HVAC systems and well-defined occupancies. Large numbers of these units are being constructed in California (CA) and elsewhere in the United States. Here, we present the design, and summarize results from a field study of four new high-performance RCs that were constructed and located at two schools. This study, supported by the California Energy Commission, was a collaboration among Lawrence Berkeley National Laboratory (LBNL), Davis Energy Group (DEG), an RC manufacturer, and two CA school districts.

The use of RCs in California schools has increased dramatically in recent years due, in part to an increasing student population and to state and federal mandates for class size reduction. An estimated 85,000 RCs are currently in place in California schools, and the numbers have been increasing at a rate of at least 10,000 per year since 2001 (Sarich, 2001; Waldman, 2001; EdSource, 2002). The most common RC configuration is a two module $7.2-\mathrm{m} \times 12-\mathrm{m}, 86-\mathrm{m}^{2}$ $\left(960-\mathrm{ft}^{2}\right)$ classroom, although a number of other styles exist, including three-module and twostory designs.

The HVAC system is a critical component of RC design from both energy and IEQ perspectives. Operating costs, electric demand, and other constraints influence HVAC design decisions such as equipment configuration, energy efficiency, and fuel source. The system also must be capable of providing adequate outdoor air ventilation since natural ventilation is often unfeasible and may be inadequate. The American Society of Heating, Refrigeration, and AirConditioning Engineers (ASHRAE) Standard 62-1999 (ASHRAE, 1999), and the State of CA Building Standards and Occupational Safety and Health Codes (CCR, 1995; CCR, Title 8) specify a minimum ventilation rate of $15 \mathrm{CFM}\left(7.5 \mathrm{~L} \mathrm{~s}^{-1}\right)$ per person in classrooms. Ventilation 
LBNL-52690

delivered at this rate will typically maintain indoor occupant-generated carbon dioxide $\left(\mathrm{CO}_{2}\right)$ at less than 1000 parts-per-million (ppm).

Standard CA RCs typically use a ducted supply-air, electric 10 Seasonal Energy Efficiency Ratio (SEER) compressor-based wall-mounted HVAC system with a direct return through the wall. These units are equipped with a movable damper that can be set to provide up to $25 \%$ of the delivered supply from outside air, providing ventilation sufficient to supply 15 CFM (7.5 L $\mathrm{s}^{-1}$ ) per person to about 30 occupants. In practice, the amount of outside air delivered to a classroom can be less due to fan on/off cycling, improper setup of the system, or poor maintenance. Additional HVAC characteristics affecting IEQ are mechanical noise and the efficacy of supply air filtration. Compressor and fan cycling noise has been reported as disruptive to learning, resulting in reduced ventilation system usage. Air filtration, which is necessary to ensure low particulate matter (PM) concentrations indoors is often minimal (i.e., 10-20\% ASHRAE dust spot efficiency) in many RC HVAC systems.

Considerable concern also has been generated regarding indoor levels of toxic and odorous volatile organic compounds (VOCs), including formaldehyde in classrooms. Careful selection of construction and interior finish materials, in combination with adequate ventilation, can reduce baseline VOC concentrations and resultant occupant exposures to these chemicals.

\section{METHODS}

The field study phases included school district and RC manufacturer recruitment, RC design specification and construction, RC installation at schools and instrumentation; field measurement and data collection during cooling and heating seasons, and data analysis. Methods are summarized below and provided in more detail by Shendell et al. 2002.

Several school districts and an RC manufacturer were recruited for participation in the study. To test the RC designs in diverse climates, we located school districts (SDs) in two distinct regions: the CA Central Valley (more extreme climate) and the San Francisco Bay Area (moderate climate). We secured agreements for placement of two high-performance RCs each at an SF Bay Area elementary school ("SDA," Cupertino) and a Central Valley elementary school ("SDB," Modesto). In the following text we refer to classrooms of type " $A$ " and " $B$ " located in $S D A$ and $S D B$ as SDA-A, SDA-B, SDB-A, and SDB-B. 
The high performance RC design used in this study combines available energy efficient construction materials and methods including additional wall, floor, and ceiling insulation; ceiling vapor barrier; "Cool Roof" reflective roof coating, low-emissivity window glazing; and efficient (T8) fluorescent lighting (DEG, 2000). Each of the four study RCs were equipped with two HVAC systems: a standard 10 SEER heat-pump air conditioning system (HPAC), and an energy-efficient indirect/direct evaporative cooler (IDEC) which is suitable for use where outdoor summertime humidities are moderate to low. The IDEC supplies continuous ventilation at $\geq 15$ CFM $\left(7.5 \mathrm{~L} \mathrm{~s}^{-1}\right)$ person ${ }^{-1}$, even when heating or cooling is not required. Additionally, compared to the standard heat-pump system, it consumes about 70\% less cooling energy. As it has no compressor and a quiet fan, the noise output from the system is lower. Incorporated into the IDEC is an $85 \%$ efficient (annual fuel utilization efficiency) gas-fired hydronic space heating system and an inlet filter system with 65\% ASHRAE dust spot efficiency (Apte et al., 2001). Both the IDEC and the HPAC system controls, as currently designed, require that the system be turned on in order to provide the required ventilation. In the case of the heat pump system, this action is tied to the temperature set point, such that outside air is only supplied when heat or cooling is needed. The IDEC system supplied room air through three 2' square ceiling diffusers evenly spaced across the length of the RC, while the HPAC systems used only two.

To study VOC source reduction potential, SDA-A and SDB-A received alternative low-VOC emitting wall panels, carpet, and ceiling panels (Hodgson et al., 2001 and 2002). Target VOCs considered toxic air contaminants listed by the state of California and odorous compounds (Hodgson et al., 2001). RCs identified as SDA-B and SDB-B were constructed using the manufacturer's standard materials, and all four RCs were otherwise constructed identically. One exception was that Nylon-6,6 broadloom carpet was installed in SDA-B while SDB-B received Nylon-6 broadloom carpet, resulting in slightly different VOC emissions profiles, as discussed below.

Two high-performance RCs were sited side-by-side at each of the schools prior to the fall 2001 semester. They were occupied and used by $3^{\text {rd }}$ and $4^{\text {th }}$ grade classes consisting of about 20 and 30 students in SDB and SDA, respectively, and one teacher. During nine weeks of the 2001 fall cooling season and nine weeks of the following heating season, the two RCs at each school 
LBNL-52690

were simultaneously operated with either the HPAC or the IDEC unit, alternated weekly. Each $\mathrm{RC}$ was instrumented to measure a range of IEQ and energy parameters (Table 1). Indoor and outdoor $\mathrm{CO}_{2}$ concentrations were measured continuously. The particle counters measure particle number concentrations in six size ranges from 0.3 to 10 micrometers. Real-time data were stored as 6-minute averages to a central data acquisition system (CDAQS) operated continuously. Particle mass concentration was calculated from particle count concentration, based upon bin size diameter and an assumed density of $2 \mathrm{~g} \mathrm{cc}^{-1}$. During the study period, the RCs were each visited by a technician once a week (typically Tuesday or Thursday). Data stored on the CDAQS was retrieved. Integrated, schoolday (7-8 hr) indoor and outdoor VOC and aldehyde samples were collected and later analyzed. A thermal comfort cart, designed and constructed at LBNL based upon ASHRAE 55-1992 thermal comfort standard (ASHRAE, 1992), was operated in three locations in each classroom. Observational information on HVAC usage and an inventory of cleaning and classroom supplies were collected (Shendell et al., 2002). At the end of the weekly technician visit, the system operation was switched from HPAC to the IDEC, or visa-versa.

Participating teachers and school custodians received training on the operation of the two HVAC systems and were briefed on field visit procedures and the schedule of weekly system switching. In order not to bias the teachers' behavior, we avoided discussing IEQ issues with the teachers and simply described the project as a study to test a new energy-efficient HVAC system. We instructed them to turn the IDEC on at the beginning of the school day as it runs automatically, but to use the HPAC system as they would normally.

\section{RESULTS AND DISCUSSION}

The patterns of operation of HVAC systems by the teachers directly influenced classroom IEQ parameters during the school day. As noted, both systems, as currently designed, must be turned on in order to provide the required ventilation. The heat pump thermostat does provide a "Fan Only" setting, but the teachers may prefer not to use it due to reported fan noise. The IDEC control requirement is simply to be on during occupancy, since the fan provides continuous $100 \%$ outside air when it is operational. In some cases, the decision to not turn the systems on is based upon a desire to save energy. For example, one teacher in the study regularly opened the $\mathrm{RC}$ windows during the morning instead of running the HVAC. In general, doors and windows were left open more frequently during the cooling season. 
Table 2 presents summarized indoor $\mathrm{CO}_{2}$, indoor-outdoor formaldehyde, indoor PM concentrations. Indoor sound level, and daily HVAC operation costs are also presented. These data are averaged across the study RCs by cooling and heating seasons, and by HVAC system type. The PM concentrations are presented as mass concentrations in three nested size bin ranges: $0.3 \mu \mathrm{m}, 0.3-1.0 \mu \mathrm{m}$, and $0.3-5.0 \mu \mathrm{m}$. Use of multiple size ranges facilitates the assessment of the effectiveness of the inlet filters and system operation.

During the cooling season, average schoolday indoor $\mathrm{CO}_{2}$ concentrations across study $\mathrm{RCs}$ were $960 \pm 480$ ppm (average \pm standard deviation) and $830 \pm 530 \mathrm{ppm}$ for HPAC and IDEC weeks, respectively. We observed teacher operation of the HVAC systems was not solely based upon thermal demand. In addition, they did not always turn the IDEC on in the morning as instructed. During periods when the teachers did not turn on the HVAC system, the $\mathrm{CO}_{2}$ concentrations in the classrooms were observed to rise well above $1000 \mathrm{ppm}$, with peaks reaching almost $3000 \mathrm{ppm}$, irrespective of the HVAC system. During periods of window-only use, indoor $\mathrm{CO}_{2}$ levels often exceeded 1000 ppm indicating that windows alone may not have provided adequate ventilation. The teachers' behavior was similar in the heating season, but the morning heating demands led to more consistent use of the IDEC. Mean heating season indoor $\mathrm{CO}_{2}$ concentrations were $1370 \pm 630 \mathrm{ppm}$ and $760 \pm 370 \mathrm{ppm}$ for HPAC and IDEC weeks, respectively. The substantially lower $\mathrm{CO}_{2}$ concentrations during IDEC operation weeks demonstrate the benefits of continuous, adequate ventilation.

The continuous ventilation provided by the IDEC system was effective for controlling the concentrations of indoor-generated pollutants as demonstrated by the formaldehyde data. Schoolday formaldehyde concentrations in both the cooling and heating seasons were higher during HPAC weeks than during IDEC weeks. Cooling season means were $21 \pm 5 \mathrm{ppb}$ and $8 \pm 3$ ppb, respectively, for HPAC and IDEC weeks. Heating season means were $14 \pm 9$ ppb and $4.5 \pm 1.3 \mathrm{ppb}$, respectively. Lower formaldehyde concentrations during the heating season likely were the result of aging of the source materials.

Indoor PM concentrations were generally higher than outdoors indicating that the occupant activities were a source of particles. During the cooling season with frequent door and window use there was increased infiltration of PM from outdoors. Indoor PM concentrations were lower 
LBNL-52690

on average during HPAC operation across the size distribution, but they occasionally reached very high levels in both HVAC modes. During cooling weeks, the HPAC's recirculation of air through a low efficiency filter may have been more effective than the $65 \%$ efficient single-pass filtration of the IDEC. During the heating season, the IDEC operation weeks had about 33\% lower mean indoor PM concentrations, but higher maximum levels. Overall, the indoor PM concentrations were much lower during the heating season.

The RC sound levels were very consistent across HVAC system and season, averaging just below $56 \mathrm{dBA}$. A comparison of occupied and unoccupied time periods showed that most of the noise increase above background in the occupied classrooms was due to the occupants themselves, with the HPAC and IDEC system operation contributing up to $14 \mathrm{dBA}$ and 11 $\mathrm{dBA}$, respectively. The data in Table 2 indicate that the distribution of sound levels was slightly higher during IDEC weeks. This finding does not agree with comments by the teachers saying that the IDEC operated very quietly. It is possible that the sound measurement location led to an upward bias in noise level during IDEC operation due to its closer proximity to the nearest IDEC supply diffuser than to the nearest HPAC diffuser.

Figure 1 depicts average indoor-outdoor VOC and aldehyde concentrations during IDEC operation in the cooling season (formaldehyde concentrations were divided by 10 for scaling). In classroom SDA-A, constructed with selected alternative materials, these VOCs were at consistently lower concentrations than in classroom SDA-B (standard materials). In the other school district the pattern is not as clear. The source of the elevated formaldehyde and acetaldehyde levels in classroom SDB-A may have been teaching and art materials introduced into the room during the semester. The elevated formaldehyde levels in that RC were transient, and dropped after a few weeks. The season average caprolactam concentration was $4.8 \mathrm{ppb}$ in in classroom SDB-B (not shown in Fig. 1), the only RC where Nylon-6 broadloom carpet was installed. Low to non-detectable caprolactam concentrations occurred in the other classrooms.

The measured concentrations of toxic or odorous VOCs across study classrooms are relatively low. During the fall 2001 cooling season with the IDEC systems in operation, only the average indoor minus outdoor concentrations of formaldehyde exceeded $5 \mathrm{ppb}$, and the concentrations of the majority of the target VOCs were under $1 \mathrm{ppb}$. These results indicate that neither the standard nor the selected alternate materials were substantial sources of these compounds. This 
LBNL-52690

finding was in agreement with the results of the laboratory study of standard and alternate materials conducted prior to the field investigation. Thus, the effects attributable to the use of alternate materials in these classrooms were small and continuous ventilation supplied by the IDEC system had a relatively greater impact on maintaining indoor VOC concentrations at low levels.

Table 2 shows that the average energy costs for operating the HVAC during the cooling and heating seasons were lower with the IDEC/hydronic gas heat system than for the HPAC system. On average, cooling costs were halved and heating costs reduced by about 30 percent, while more outside air was concurrently provided for ventilation. These results, overall suggest that it is possible to use efficient engineering solutions to simultaneously reduce energy consumption and improve indoor environmental quality.

\section{ACKNOWLEDGEMENTS}

The authors thank the school district and manufacturer personnel for their participation. This study was sponsored by the California Energy Commission through the Public Interest Energy Research program as Element 6.2.2 of the Lawrence Berkeley National Laboratory High Performance Commercial Buildings Systems research CEC Contract Number 400-99-012. The study was additionally supported by the U.S. Department of Energy under Lawrence Berkeley National Laboratory contract number DE-AC03-76SF00098.

\section{REFERENCES}

Apte MG, Delp WW, Diamond RC, et al. 2001. Report on HVAC Option Selections for a Relocatable Classroom Energy and Indoor Environmental Quality Field Study, LBNL49026, Lawrence Berkeley Laboratory, University of California, Berkeley, CA 94720.

ASHRAE. 1992. Thermal Environmental Conditions for Human Occupancy, Atlanta, GA, American Society of Heating, Refrigerating, and Air Conditioning Engineers (ANSI/ASHRAE Standard 55-1992).

ASHRAE. 1999. Ventilation for acceptable indoor air quality, Atlanta, GA, American Society of Heating, Refrigerating, and Air Conditioning Engineers Standard 62-1999).

CCR, CA Code and Regulations Title 24, Part 6. Energy efficiency standards for residential \& nonresidential buildings, July 1995.

CCR, CA Code and Regulations Title 8 §5142 \& Title 24 §121(c). 
LBNL-52690

DEG. 2000. Premium Efficiency Relocatable Classroom Performance Assessment in PG\&E Territory, PG\&E Internal Report from Davis Energy Group dated 12/29/2000, PG\&E Project Manager Larry Stevens, Pacific Gas and Electric Company, San Francisco, CA. EdSource. 1998. EDSource online, internet access: http://www.edsource.org/

Fisk WJ. 2000. Health and productivity gains from better indoor environments and their relationship with building energy efficiency. Annual Reviews of Energy and the Environment, 25:537-566.

Hodgson AT, Fisk WJ, Shendell DG, Apte MG. 2001. Predicted Concentrations in New Relocatable Classrooms of Volatile Organic Compounds Emitted from Standard and Alternate Interior Finish Materials, LBNL-48490. Lawrence Berkeley Laboratory, University of California, Berkeley, CA 94720.

Hodgson AT, Apte MG, Shendell DG, Beal D, McIlvaine JER. 2002. Implementation of VOC Source Reduction Practices in a Manufactured House and in School Classrooms. Presented at Indoor Air 2002, The $9^{\text {th }}$ International Conference on Indoor Air Quality and Climate, Monterey, CA, June 30 to July 5, 2002, Vol 3: 576-581.

Sarich. D. 2001. Personal communication with Dan Sarich, American Modular Systems, Manteca CA.

Shendell, DG, Di Bartolomeo, D, Fisk, WJ, Hodgson, AT, Hotchi, T, Lee, S-M, Sullivan, DP, Apte, MG, Rainer, LI. 2002. Final Methodology for a Field Study of Indoor Environmental Quality and Energy Efficiency in New Relocatable Classrooms in Northern California. LBNL-51101. Lawrence Berkeley National Laboratory. Berkeley, CA. 94720.

Waldman. 2001. Personal Communication with Jed Waldman, California Department of Health Services, Indoor Air Branch, June 6, 2001. 
Table 1. IEQ and energy monitoring instrumentation in study relocatable classrooms.

\begin{tabular}{|c|c|c|}
\hline Parameter & Method ${ }^{1}$ & Location $^{2}$ \\
\hline \multicolumn{3}{|c|}{ Continuous: } \\
\hline Carbon Dioxide & NDIR & $\mathrm{I}, \mathrm{O}$ \\
\hline Particle size, count & Laser Counter & $\mathrm{I}, \mathrm{O}$ \\
\hline Relative Humidity & Capacitance & $\mathrm{I}, \mathrm{O}, \mathrm{HPD}, \mathrm{ID}, \mathrm{TC}, \mathrm{C}$ \\
\hline Temperature & Thermistor & $\mathrm{I}, \mathrm{O}, \mathrm{HPD}, \mathrm{ID}, \mathrm{TC}, \mathrm{C}$, \\
\hline Air Velocity & Thermo-anemometer & TC \\
\hline Sound Level & dB, A-wtd., Leq & $\mathrm{C}$ \\
\hline Door open & Door sensor & Door \\
\hline Window position & LDP & \\
\hline Wind speed, dir. & Anemometer & $\mathrm{O}$ \\
\hline Electricity & Current transducer & HVAC, Lights, Total \\
\hline Natural Gas & Gas meter & IDEC Heating \\
\hline \multicolumn{3}{|c|}{ Time-averaged: } \\
\hline $\mathrm{VOC}^{3}$ & Multisorb GC/MS & $\mathrm{I}, \mathrm{O}$ \\
\hline Formaldehyde, acetaldehyde ${ }^{3}$ & $\begin{array}{l}\text { DNPH } \\
\text { HPLC UV detector }\end{array}$ & $\mathrm{I}, \mathrm{O}$ \\
\hline Thermal Comfort $^{4}$ & ASHRAE 55-1992 & $\mathrm{I}(0.1 \mathrm{~m}, 0.5 \mathrm{~m}, 1.1 \mathrm{~m})$ \\
\hline
\end{tabular}

${ }^{1} \mathrm{NDIR}=$ non-dispersive infrared; multisorb $=$ multisorbent tubes; GCMS $=$ gas chromatography/mass spectrometry; HPLC=high performance liquid chromatography w/UV detection; LDP = linear displacement potentiometer; A-wtd=A-weighted, Leq = equivalent noise level ${ }^{2} \mathrm{I}=$ Indoors, $\mathrm{O}=$ Outdoors, $\mathrm{HPD}=$ Heat pump system diffuser, $\mathrm{ID}=\mathrm{IDEC}$ Diffuser, $\mathrm{TC}=$ thermal comfort cart, $\mathrm{C}=$ Indoors@ $2.5 \mathrm{~m}$, center of $\mathrm{RC}, \mathrm{m}=$ meters above floor ${ }^{3}$ See Hodgson et al., $2001{ }^{4}$ See ASHRAE, 1992 
LBNL-52690

Table 2. Summary schoolday statistics averaged across four occupied high performance relocatable classrooms monitored during 9-10 weeks in each of the cooling and heating seasons in Northern California during the 2001-2002 school year. 10 SEER HPAC refers to heat pump air conditioner weeks and IDEC refers to Indirect/Direct Evaporative Cooler weeks of operation, respectively.

\begin{tabular}{|c|c|c|c|c|c|c|c|}
\hline \multicolumn{2}{|c|}{ COOLING SEASON } & \multicolumn{3}{|c|}{10 SEER HPAC } & \multicolumn{3}{|c|}{ IDEC } \\
\hline Measurement & Units & Uean \pm Std & $\operatorname{Max}$ & $95^{\text {th }} \%$ & Mean \pm Std & Max & $95^{\text {th }} \%$ \\
\hline Indoor Tem & ${ }^{\circ} \mathrm{F}$ & $72 \pm 3.9$ & 82 & 78 & $71 \pm 3.8$ & 80 & 76 \\
\hline Outdoor Temperature & ${ }^{\circ} \mathrm{F}$ & $82 \pm 8.7$ & 104 & 98 & $77 \pm 8.0$ & 104 & 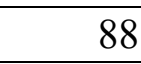 \\
\hline Indoor $\mathrm{CO}_{2}$ & ppm & $960 \pm 480$ & 2770 & 1950 & $830 \pm 530$ & 2880 & 163 \\
\hline $\mathrm{HCHO}^{1}$ & $\mathrm{ppb}$ & $21 \pm 5$ & 28 & 28 & $8.0 \pm 2.8$ & 19 & 19 \\
\hline $\mathrm{PM}^{2}(0.3-5 \mu \mathrm{m})$ & $\mu \mathrm{g} \mathrm{m}^{-3}$ & $240 \pm 260$ & 1500 & 830 & $360 \pm 380$ & 3000 & 100 \\
\hline $\mathrm{PM}(0.3-1 \mu \mathrm{m})$ & $\mu \mathrm{g} \mathrm{m}^{-3}$ & $20 \pm 17$ & 140 & 51 & $28 \pm 35$ & 270 & 76 \\
\hline $\mathrm{PM}(0.3 \mu \mathrm{m})$ & $\mu \mathrm{g} \mathrm{m}^{-3}$ & $5.0 \pm 3.4$ & 17 & 11 & \pm 6.1 & 49 & 18 \\
\hline Indoor Sol & $\mathrm{dBA}$ & $7 \pm 9.7$ & 84.2 & 69.1 & $55.9 \pm 10.5$ & 90.8 & 70. \\
\hline HVAC Ene & \$/day & $0.96 \pm 0.39$ & 1.65 & 1.65 & 0.27 & 1.23 & 0. \\
\hline \multicolumn{2}{|c|}{ HEATING SEASON } & \multicolumn{3}{|c|}{10 SEER HPAC } & \multicolumn{3}{|c|}{ IDEC } \\
\hline Measurement & Units & Mean \pm Std & Max & $95^{\text {th }} \%$ & Mean \pm Std & Max & $95^{\text {th }} \%$ \\
\hline Indoor Ten & ${ }^{\circ} \mathrm{F}$ & $70 \pm 5.4$ & 88 & 80 & $71 \pm 5.1$ & 92 & 8 \\
\hline Outdoor Temperature & ${ }^{\circ} \mathrm{F}$ & $59 \pm 9.5$ & 86 & 76 & $59 \pm 7.5$ & 88 & 73 \\
\hline Indoor $\mathrm{CO}_{2}$ & ppm & $1370 \pm 630$ & 3140 & 2379 & $760 \pm 370$ & 2600 & 1527 \\
\hline $\mathrm{HCHO}^{1}$ & $\mathrm{ppb}$ & $14 \pm 9$ & 34 & 34 & $4.5 \pm 1.3$ & 8.5 & 8.5 \\
\hline $\mathrm{PM}(0.3-5 \mu \mathrm{m})$ & $\mu \mathrm{g} \mathrm{m}^{-3}$ & $74 \pm 72$ & 580 & 210 & $48 \pm 49$ & 640 & 130 \\
\hline $\mathrm{PM}(0.3-1 \mu \mathrm{m})$ & $\mu \mathrm{g} \mathrm{m}^{-3}$ & $11 \pm 7.7$ & 48 & 26 & $8.3 \pm 6.4$ & 130 & 1 \\
\hline $\mathrm{PM}(0.3 \mu \mathrm{m})$ & $\mu \mathrm{g} \mathrm{m}^{-3}$ & $3.8 \pm 3.2$ & 16 & 10 & $3.2 \pm 2.8$ & 15 & 8.0 \\
\hline Indoor Sound Level & $\mathrm{dBA}$ & $55.5 \pm 9.6$ & 78.0 & 68.3 & $55.9 \pm 10.5$ & 86.8 & 70.7 \\
\hline HVAC Energy Cost ${ }^{2}$ & $\$ /$ day & $1.54 \pm 0.79$ & 3.60 & 2.90 & $1.03 \pm 0.61$ & 3.53 & 2.1 \\
\hline
\end{tabular}

${ }^{1}$ Indoor - outdoor formaldehyde concentration

${ }^{2} \mathrm{PM}=$ Particulate Matter in given instrument bin sizes, mass concentration calculated from particle count concentration, based upon bin size diameter and assumed density of $2 \mathrm{~g} \mathrm{cc}^{-1}$. Outdoor PM concentrations $(0.3-5 \mu \mathrm{m})$ were $130 \pm 140 \mu \mathrm{g} \mathrm{m}^{-3}$ and $30 \pm 40 \mu \mathrm{g} \mathrm{m}^{-3}$ in the cooling and heating seasons, respectively.

${ }^{3}$ Assuming electricity cost of $\$ 0.14 \mathrm{kWh}^{-1}$ and natural gas cost of $\$ 0.60$ therm $^{-1}$ 


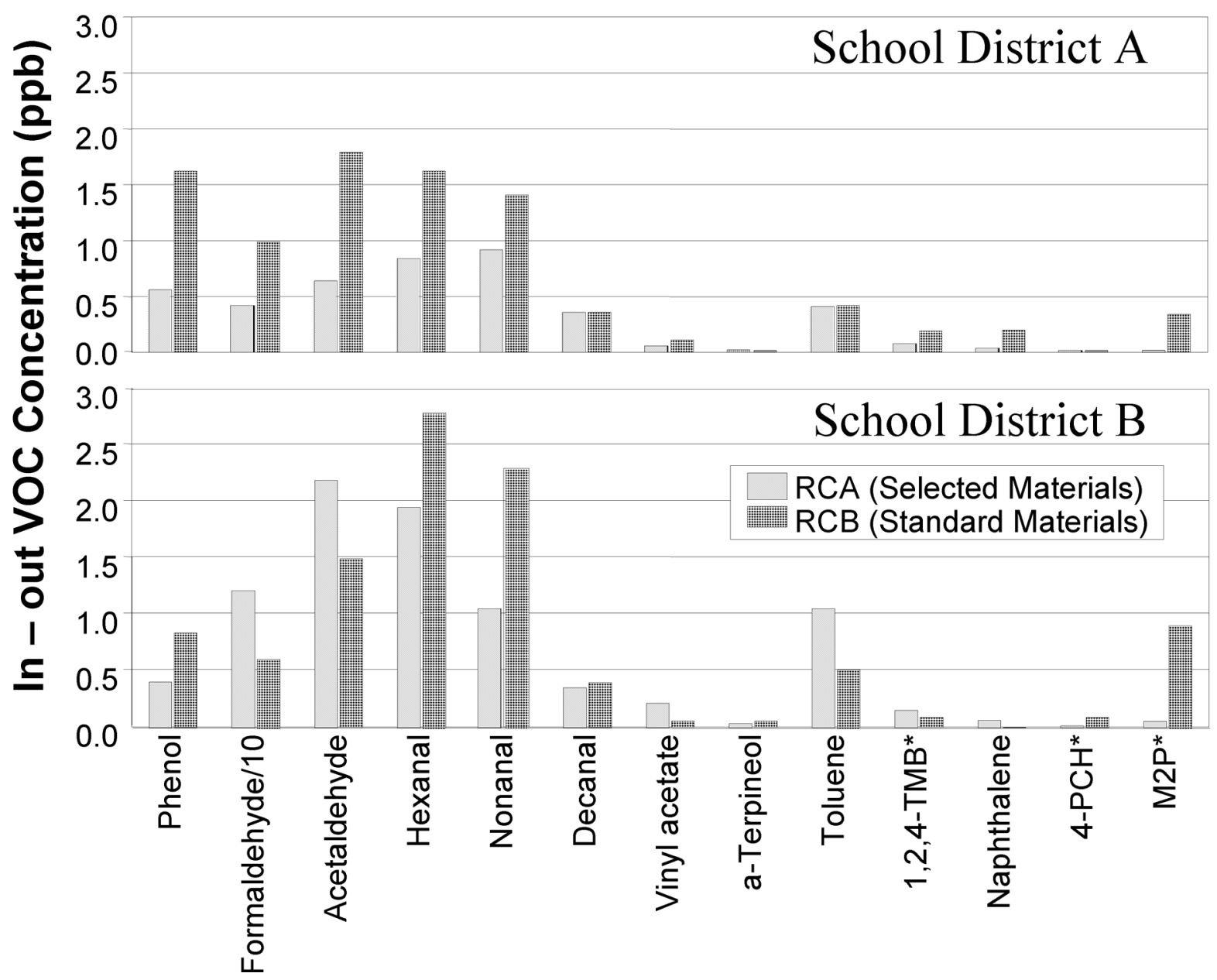

Figure 1. Comparison of selected toxic or odorous volatile organic compounds (VOCs) measured in RCs with alternative materials selected versus those with standard materials. Data represent average indoor minus outdoor VOC concentrations during IDEC operation weeks in the cooling season; formaldehyde concentrations are divided by a factor of 10 . VOCs labeled with asterisks are: 1,2,4-TMB = 1,2,4-trimethylbenzene; 4-PCH = 4phenylcyclohexene; M2P = 1-methyl-2-pyrrolidinone 